INTERNATIONAL JOURNAL OF SYSTEMATIC BACTERIOLOGY

Vol. 16, No. 2 April 1966 pp. 135-142

\title{
MINUTES OF IAMS SUBCOMMITTEE ON TAXONOMY OF VIBRIOS
}

The IAMS Subcommittee on Taxonomy of Vibrios met on January 29, 1965 in Honolulu, Hawaii during the occasion of the Symposium on Cholera Research held at the EastWest Center at the University of Hawaii. Members present were Dr. Rudolph Hugh (Chairman), Dr. John C. Feeley (Secretary), Dr. S. Mukerjee, and Dr. R. Sakazaki. Dr. Charles R. Manclark was absent. Dr. D. L. Shrivastava attended as an observer at the invitation of the Chairman.

The following matters were discussed and action taken as follows:

1. The Subcommittee agreed unanimously to support the proposal by Hugh (Int. Bull. Bact. Nom. and Taxon. 14:87101,1964 ) that ATCC strain 14035 (NCTC 8021) be designated the neotype strain of Vibrio cholerae Pacini 1854.

2. The Subcommittee agreed unanimously to support the proposal by Hugh (Int. Bull. Bact. Nom. and Taxon. 15-6168, 1965) that ATCC strain 14033 (NCTC 8457) be designated the neotype strain of Vibrio eltor Pribram 1933.

3. The Subcommittee discussed at some length the question of whether Vibrio cholerae and Vibrio eltor should be recognized as two distinct species or as a single species. It was noted that historically $\underline{\mathrm{V}}$. eltor (or the so-called "El Tor vibrio") was differentiated from $\underline{V}$. cholerae solely on the basis of the haemolytic properties of the former. Difficulties with detection of haemolytic activity have led to the utilization of other differential criteria such as bacteriophage sensitivity, chicken-erythrocyte agglutination, Voges-Proskauer reactivity, polymixin B sensitivity, growth in trypsin broth, soda-agglutination, and sublimate precipitation (vide Felsenfeld, Bacteriol. Rev. 28:72-86, 1964; Hugh, Int. Bull. Bact. Nom. and Taxon. 15:61-88, 1965). The problem is now complicated by the appearance of strains which are partially or completely lacking in haemolytic activity but have othe $r$ characteristics of $\underline{v}$. eltor. The latter are commonly regarded by many workers as "nonhaemolytic" $\underline{V}$. eltor. In any event, there is no longer any question of the ability of the El Tor vibrio to cause epidemic cholera in man.

Drs. Hugh, Feeley, and Sakazaki held the view that the described differences between Vibrio cholerae and $\underline{V}$. eltor are insufficient for the recognition of the two organisms as 
distinct species, although they are of unquestionable epidemiologic significance.

Dr. Mukerjee agreed that the organisms were very similar, but expressed the view that differences should be indicated in some way in nomenclature. He indicated that he held no strong feelings as to whether the organisms were called $\underline{V}$. eltor or $\underline{V}$. cholerae type eltor, or by some similar designation. A minority report by Dr. Mukerjee is appended to these minutes.

4. The Subcommittee recommended the following provisional description of the genus Vibrio:

Gram-negative; asporogenous rods with a single rigid curve or straight rods; single polar flagellum; indophenol oxidase positive; produce acidity without gas from dextrose. Acidity from dextrose is produced by the Embden-Meyerhof glycolytic pathway.

It was recognized that this provisional description will not differentiate organisms in the genus Vibrio from anaerogenic strains of Aeromonas, and that further studies will be needed to reach agreement on how this definition should be emended to either include or exclude the latter similar organisms. Nevertheless, the Subcommittee noted that the definition effectively excludes organisms of the genera Comamonas and Pseudomonas which have beenclassified as Vibrio on the basis of somatic curvature.

It was also recognized that the anaerobic and microaerophilic organisms such as Vibrio fetus are of questionable relation to other members of the genus and that recommendations for their classification elsewhere have been made (vide Sebald and Véron, Ann. Inst. Pasteur, 105:897-910, 1963). Since Dr. Manclark, who is more familiar with these organisms, was absent, no recommendations were made.

5. The term "vibrio" (not capitalized) is the common or vernacular name for the genus named Vibrio and is used to refer to a bacterium or species in this genus. The subcommittee could not recommend the use of the term vibrio to refer to all bacteria with a single somatic curve. Bacteria with a single somatic curve may belong to genera other than Vibrio (viz. Aeromonas, Pseudomonas, Comamonas).

6. The Subcommittee recognized that the species Vibrio cholerae and Vibrio eltor could both be divided into Ogawa and Inaba serotypes, and noted that Feeley (J. Bacteriol. 
89:665-670,1965)had proposed division of the single species Vibrio cholerae (including $\underline{\text {. }}$ eltor) into types based on phage IV sensitivity, chicken-erythrocyte agglutination, tube and plate hemolysis, and Voges-Proskauer activity.

7. Dr. Hugh was elected Chairman and Dr. Feeley was elected Secretary to serve until the next meeting of the Subcommittee.

Respectfully submitted,

John C. Feeley, Ph. D. Secretary

\section{Minority Report by Dr. S. Mukerjee}

Within a given bacterial genus it is only to be expected that similarities in biochemical, antigenic and other characteristics will outnumber the differences. My opinion is that the criteria for species differentiation should not be numerical but qualitative in the sense whether the differences are of fundamental biological importance. The principal considerations which incline me to classify $\underline{\text {. }}$ cholerae and $\underline{V}$ : eltor in distinct species are given below in tabular form.

\section{POINTS OF DIFFERENTIATION BETWEEN VIBRIO CHOLERAE AND VIBRIO ELTOR}

\section{Historical Considerations:}

Vibrio cholerae has been known to be associated with classical cholera since it was first identified as the causative organism of cholera by Robert Koch in 1883. It has been isolated from stool samples of patients suffering from cholera which at one time spread to most countries of the world and since 1923 has been limited to a few Asian countries. From 1962 classical cholera is known to occur only in India and Pakistan.

Vibrio eltor was isolated for the first time by Gotschlich in 1906 in the El Tor quarantine station from the intestines of patients who died of diseases other than cholera. In fact, the pilgrimage of that year was entirely free from cholera. Since then this type of vibrio has been frequently isolated in the Middle East countries from water sources as well as 
from healthy persons or cases with symptoms of mild diarrhoea. This type of vibrio has also been found in other areas in the absence of cholera El Tor. For many years V. eltor was considered apathogenic or only mildly pathogenic. This led van Loghem (1932) to remark that El Tor disease and cholera asiatica should be considered different diseases aetiologically.

In September $1937 \mathrm{~V}$. eltor strains were for the first time isolated from cholera-like cases in South Celebes in Indonesia where the disease remained confined for several decades. Since 1961 cholera El Tor has come out of its original home and has been spreading in a pandemic form involving most countries in the Southwest Pacific region and in South and Southeast Asia. Towards the end of 1963 it entered the Indo-Pakistan Subcontinent and within a year from then it has spread to wide areas in India and Pakistan. In many areas in the subcontinent classical cholera cases have now been replaced by cholera El Tor while in some other areas they co-exist in mixed outbreaks.

From the epidemiological point of view the two types of cholera infections would thus appear to be distinct and have to be differentiated not only in following the spread of infection but also in applying control measures and especially in choosing the appropriate vaccine for prophylaxis.

\section{Epidemiological Considerations:}

$$
\underline{V} \text {. cholerae } \quad \underline{V} \text { eltor }
$$

a) Nature of outbreaks (de Moor, 1963):

High morbidity rates Low morbidity rates

b) Contact carrier rates:

Low High

c) Convale scent carrier state:

Short duration

Longer duration. Occasional cases of convalescent carriers are known to exist in Philippines for as long as $1 \frac{1}{2}$ years.

d) Areas involved in outbreaks at present:

Limited to India and Pakistan
Widespread in West Pacific and South and Southeast Asian countries. 
e) Effect of artificial immunization (Preliminary results of field trials)

V. cholerae vaccine affords only partial protection

El Tor vaccine affords against classical cholera. better protection against E1 Tor vaccine has not yet been tested against cholera El Tor than classical cholera. V. chole rae vaccine.

f) Interaction in outbreaks due to mixed infections by both types of vibrios. (Mukerjee, Basu and Bhattacharya, unpublished observations). Cases of infection due to Cholera cases due to $\underline{\mathrm{V}}$. V. cholerae are soon outnumbered by those due to eltor may either com$\underline{\mathrm{V}}$. eltor. pletely or partly replace those due to $\underline{\mathrm{V}}$. cholerae.

\section{Bacteriological Considerations:}

a) Haemolytic character:

Nonhaemolytic

Usually haemolytic. If nonhaemolytic, the haemolytic characteristic may be induced by subcultures under suitable conditions. (Roy and Mukerjee, 1963)

b) Rapid agglutination of chicken erythrocytes (Finkelstein and Mukerjee, 1962)

Negative Positive

c) Polymyxin sensitivity (Gan and Tjia, 1963) Sensitive Insensitive

d) Soda-serum agglutination (Tanamal, 1959) Negative Positive

e) Soda-sublimate precipitation (Tanamal, 1959) Positive Negative

f) Phage sensitivity

1. Cholera typing phages (Mukerjee, 1963) Generally sensitive to the Generally insensitive to typing phages and univer- cholera typing phages and sally sensitive to group IV totally resistant to lysis phage by group IV phage. 
2. El Tor typing phages (Mukerjee, 1964)

Ins ensitive to groups

II, III, IV and V phages.
Sensitivity patterns

vary according to the phage-type of the strains.

g) Aerobic glycolysis (Linton, Mullick and Mitra, 1936) Positive

Negative

h) Growth characteristics:

1. Rate of growth (Mukerjee, Basu and Bhattacharya, unpublished record)

Low

High

2. Mutation in culture in respect to haemolytic character, phage sensitivity and antibiotic sensitivity (Mukerjee, 1964)

Rare

Frequent

3. Interaction in mixed cultures of $\underline{\mathrm{V}}$. cholerae and $\underline{\mathrm{V}}$. eltor (Mukerjee, Basu and Bhattacharya, unpublished observation)

In peptone water growth of $\mathrm{V}$. eltor over-grows

$\underline{V}$. cholerae ceases within $\underline{\mathrm{V}}$. cholerae.

$\overline{2}$ to 4 hours and the vibrio

may soon be eliminated.

i) Pathogenicity (for humans)

All strains are pathogenic to humans. $\underline{V}$. cholerae cannot be isolated in the absence of cholera outbreaks.

V. eltor strains may be pathogenic or apathogenic. Apathogenic strains can be isolated from areas free from cholera outbreaks.

j) Toxins:

1. Soluble haemolysin

$\mathrm{Nil}$

Usually present or can be induced

2. Lethal exotoxin for white rats (Boatman, 1936) Nil

Present

k) Cell protein components (Linton, Shrivastava and Mitra, 1935): Protein type I

Present

Protein type II

Absent
Absent

Present 
Many of the differences, which I have enumerated, appear to me to be fundamental and to sufficiently justify classification of the two vibrios into separate species. In particular, the known differences in haemolytic character, ability to agglutinate chicken erythrocytes, sensitivity to polymyxin and chemical composition of the cells point to significant differences in their biochemical potentialities. The difference in the metabolic pattern of the two groups of vibrios, namely the persistence of glycolys is under aerobic condition in $\mathrm{V}$. cholerae in contrast to its absence in $\underline{V}$. eltor is a qualitative difference of critical importance since it affects their capacity for survival under adverse nutrient conditions. The interaction observed in mixed cultures suggests an antoganism between $\underline{V}$. cholerae and $\underline{V}$. eltor, which is hardly expected in strains belonging to the same species. Differences in phage-sensitivity should also be taken into account, since they suggest a difference at the ultra-structural or molecular level.

The epidemiological manifestations of an infectious disease are closely related to the physiological properties of its causative organisms. While practical advantages related to epidemiological considerations may not be taken as essential criteria for purposes of bacterial classification, such advantages surely provide valuable support to a scheme based on strictly biological considerations. To my thinking, the known differences in the biological characteristics of the two types of vibrios go pari passu with differences in clinical and epidemiological manifestations and taken together provide a sound argument in favour of continuing the present practice of differentiating the two groups of vibrios into distinct species. As the number of species recognisable among agglutinable vibrios are limited to two only, there is also no question of any complications arising from a multiplicity of species being included in this genus, as in Salmonella.

\section{REFERENCES}

Boatman, T.P.J. 1936. Thesis, Amsterdam (Quoted by de Moor, 1963).

Finkelstein, R.A. and S. Mukerjee. 1963. Proc. Soc. Exptl. Biol. Med. 112:335.

Gan, K. H. and S. K. Tjia. 1963. Amer. Jour. Hyg. 77: 184.' 
Kraus, R. and R. Pribram. 1905. Wien Klin. Wschr. 18: 999.

Linton, R. W. , B. N. Mitra, and D. N. Mullick. 1936. Indian Jour. Med. Res. 23:589. D. L. Shrivastava, and B. N. Mitra. 1935. Indian Jour. Med. Res. 22:633. 